\title{
COMMERCIAL BANK LOANS AND NON-METROPOLITAN ECONOMIC ACTIVITY: A QUESTION OF CAUSALITY
}

\author{
David L. Barkley and Peter E. Helander*
}

\begin{abstract}
The Granger test for causality was applied to 1975-1980 loan and retail sales data for 27 non-metropolitan Arizona communities to determine if banks have played an active or passive role in community development. Regression results for Arizona indicate that bank lending was sensitive to past local economic activity. No statistical evidence was found to indicate that bank lending leads local economic development.
\end{abstract}

\section{Introduction}

The growth of non-metropolitan communities is often attributed to the ability of these communities to attract or develop basic (exporting) industries. An expanding basic sector will create employment opportunities in the basic industry itself, and through backward and forward linkages generate additional sales, employment, and income in the nonbasic or service sector of the local economy. The cumulative change in a community's economic activity will usually exceed the change in sales, employment, and income experienced by the basic industry. The difference between the cumulative and initial effects is determined by the magnitude of the local multipliers. According to McGee (1970), commercial banks can take an active role in this process if they induce the development of the export sector by making available loanable funds at competitive rates of interest. In this case, bank lending could be considered exogenous to the growth process. Alternatively, economic growth will generate income which will in turn increase the deposits and reserves of local banks. With

\footnotetext{
*Associate Professor of Agricultural Economics, University of Arizona, and former Research Assistant, Department of Agricultural Economics, University of Arizona. The financing of this research was provided by the University of Arizona, Agricultural Experiment Station, under Western Regional Project W-165. The authors would like to thank Dennis Cory, Eric Monke, Michael Ransom and Anonymous reviewers for helpful comments on this manuscript.
}

greater reserves, local banks are able to expand loans to support the growth process and the cycle continues. However, if banks merely respond to the increase in demand for loans resulting from increased economic activity, the bank's portfolio management behavior is considered "passive" with respect to the growth process (McGee). Clearly, both "active" and "passive" lending policies will facilitate the growth of non-metropolitan communities. However, Minsky (1965) noted that the role of commercial banks is greatest if they both initiate export activity as well as respond to the credit needs of the nonbasic sector. ${ }^{1}$

Many of the earlier studies of the relationship between commercial bank lending and economic growth have implied that commercial bank performance affects local economic activity. For example, Minsky (1965) stated that banks played a central role in California's rapid growth. Macesish (1965) found a negative correlation between county per capita income and bank assets held in liquid form, and he concluded that the holding of liquid assets could hinder regional development. Griggs and Petty (1970) reported a positive and significant correlation between bank lending and local economic growth. Ho and Shaffer (1979) estimated the impact of bank outputs on local economic growth within a simultaneous framework and concluded that the amount of loans had a positive and significant impact on the change in per capita income. The consensus of this research is that the relationship between bank lending and local economic activity is bidirectional. That is, commercial banks both initiate and respond to local economic growth.

In contrast to the above research, Dreese (1974) also found a significant positive relationship between loan volume and employment. However, he stated that his results did not imply a particularly significant role for banks in the regional growth process. Dreese noted that his findings indicated only that loans and employment are positively correlated and that "the direction of causality might easily be from employment to loan growth rather than the reverse" (p. 656).

The absence of a consensus in the literature 
on the role of banks in economic growth may result from these studies' reliance on cross sectional data bases and their inability to distinguish between correlation and causality. ${ }^{2}$ The question of causality is essentially a dynamic phenomena and the use of time series data and estimation procedures may provide additional insight into the causal relationship between bank performance and economic development. The purpose of this research is to use time series data and the Granger statistical test of causality to determine if loans lead economic activity or if loan volume simply responds to changes in local economic activity. The results suggest that bank lending is sensitive to past local economic activity. However, no evidence is found to support the null hypothesis that bank lending plays a major role in initiating local economic growth. The methodology, analysis, and findings from which the above conclusions are derived are presented in the following sections.

\section{Granger Test for Causality}

Granger (1969) has provided a testable definition of causality between two stochastic time series ( $X$ and $Y$ ) based on the criterion that if optimum predictions of $Y$ conditional on past values of $Y$ and $X$ are significantly better than optimum predictions conditional on past values of $\mathrm{Y}$ alone, then $\mathrm{X}$ is said to "cause" $\mathrm{Y}$. A formal statistical test for Granger's definition of causality involves regressing current values of one time series $(Y)$ on past values of $Y$ and $X$. Then the regressions are reversed and current values of $X$ are regressed on past values of $Y$ and $X$. The regression equations may be represented by the following autoregressive processes:

$$
\begin{aligned}
& Y_{t}=\alpha_{0}+\sum_{i=1}^{n} \alpha_{1 i} Y_{t-i}+\sum_{i=1}^{m} \alpha_{2 i} X_{t-i}+\epsilon_{1 t} \\
& X_{t}=\beta_{0}+\sum_{i=1}^{r} \beta_{1 i} X_{t-i}+\sum_{i=1}^{s} \beta_{2 i} Y_{t-i}+\epsilon_{2 t}
\end{aligned}
$$

where $\epsilon_{1 t}$ and $\epsilon_{2 t}$ are taken to be two uncorrelated white-noise series.

The time series $\mathrm{X}$ is said to "Granger-cause" $\mathrm{Y}$ or $\mathrm{X}$ is said to contain "information exploitable in forecasting" $Y$ if one can reject the null hypothesis that the $\alpha_{2}$ 's are jointly zero. Alternatively, to test if $Y$ "causes" $X$ in the Granger sense is equivalent to testing whether the coefficients of lagged $Y\left(\beta_{2}{ }^{\prime} s\right)$ are zero. If both $X$ and $Y$ are exogenous the $\alpha_{2}$ 's and $\beta_{2}$ 's will be jointly significantly different from zero, and bidirectional causality or feedback is said to occur. Finally, if $X$ does not cause $Y$ and $Y$ does not cause $X$ then $X$ and $Y$ are said to be independent. In this case, neither the $\alpha_{2}$ 's nor $\beta_{2}$ 's are jointly significantly different from zero. $^{3}$

\section{Data and Model Specification}

Annual time series for bank credit and economic activity are required to test for causal relationships between commercial bank lending and economic growth. Retail sales were selected as the proxy for local economic activity, since accurate annual estimates of traditional measures of economic development (per capita income and employment) are not available by community. Retail sales estimates for 27 nonmetropolitan communities were available from community sales tax collection data for the fiscal years 1975-76 through 1980-81. Commercial bank lending activity in the 27 communities was measured by the 1975-1980 yearend balances of outstanding loans for the communities' branch bank offices. ${ }^{4}$

The retail sales and loan data for the 27 communities were deflated to 1972 dollars and expressed as an index of their respective deflated 1975 values. ${ }^{5}$ These adjustments reduce the likelihood of statistical problems inherent in estimation with data from cities of different sizes. Next the deflated indices of retail sales and loans were combined to form a pooled time series cross-sectional sample with 162 observations. ${ }^{6}$ The sample exhibits substantial variability in economic activity and loan volume and should provide a valid data base for econometric analysis. For example, for the 27 cities selected, the 1975 to 1980 community growth rates in real retail sales and loans outstanding ranged from negative 20 to positive 114 percent and negative 31 to positive 291 percent, respectively.

The Granger test for causality presented in equations (1) and (2) is a test for the relationship between current loans and past loans and retail sales and the current sales versus past sales and loans. This specification would be appropriate for the loan-economic activity causality test for one community. However, for a pooled time series cross-sectional sample, local 
economic and bank market characteristics which may contribute to intercommunity differences in retail sales or loan activity should be included in the regression equations. For example, the local demand for loanable funds may be affected by the community's industrial structure. Mining and manufacturing firms are more likely to be non-locally owned than businesses engaged in agriculture, services, and trade, and therefore, the credit needs of mining and manufacturing firms are more likely to be provided by the firm's home offices through nonlocal credit sources. A variable representing the percentage of 1980 county employment in mining and manufacturing (MM) is included and hypothesized to be negatively related to local bank loans. The location of a community with respect to other communities which offer similar or higher-ordered goods and services, may also affect a community's sales and lending activity. That is, communities that are geographically isolated should experience less intercity competition for loan and retail sale customers, and as a result, fewer leakages. The potential for leakages in community loan and sales activity is represented by the distance to the nearest' city of equal or greater population (D), and D is hypothesized to be positively related to local loans and sales. A dummy variable (CS) for the existence of alternative credit sources (savings and loan associations, credit unions, loan companies) is included to test for the influence of differences in the competitive structure of local financial markets on local loan activity. A negative relationship between CS and bank loans is anticipated. Finally, due to the national recession, sales and loans in Arizona's non-metropolitan communities declined in 1979 and 1980. Thus, a trend variable $(t)$ is included to capture the influence of external forces on community sales and loans. The coefficient of the trend variable is hypothesized to have a negative sign.

Two alternative specifications of the Granger test for bank lending-economic activity causality were estimated using the pooled time series cross-sectional data base and OLS regression. The stochastic models take the following forms:

\section{(3) Loans versus Sales}

$L_{i t}=f_{1}\left(L_{i t-1}, L_{i t-2}, S_{i t-1}, S_{i t-2}, M M_{i}, D_{i}, C S_{i}, t, \epsilon_{i t}\right)$
$S_{i t}=f_{2}\left(S_{i t-1}, S_{i t-2}, L_{i t-1}, L_{i t-2}, M_{i}, D_{i}, C S_{i}, t, \epsilon_{i t}\right)$

(4) Change in Loans versus Change in Sales

$$
\begin{aligned}
\Delta \mathrm{L}_{\mathrm{it}}= & \mathrm{f}_{3}\left(\Delta \mathrm{L}_{\mathrm{it}-1}, \Delta \mathrm{L}_{\mathrm{it}-2}, \Delta \mathrm{S}_{\mathrm{it}-1}, \Delta \mathrm{S}_{\mathrm{it}-2}, \mathrm{MM}_{\mathrm{i}}, \mathrm{D}_{\mathrm{i}},\right. \\
& \left.\mathrm{CS}_{\mathrm{i}}, \mathrm{t}, \epsilon_{\mathrm{it}}\right) \\
\Delta \mathrm{S}_{\mathrm{it}}= & \mathrm{f}_{4}\left(\Delta \mathrm{S}_{\mathrm{it}-1}, \Delta \mathrm{S}_{\mathrm{it}-2}, \Delta \mathrm{L}_{\mathrm{it}-1}, \Delta \mathrm{L}_{\mathrm{it}-2}, \mathrm{MM}_{\mathrm{i}}, \mathrm{D}_{\mathrm{i}},\right. \\
& \left.\mathrm{CS}_{\mathrm{i}}, \mathrm{t}, \epsilon_{\mathrm{it}}\right)
\end{aligned}
$$

where: $L_{i t}=$ Index of deflated loans for community $i$, period $t$

$S_{i t}=$ Index of deflated retail sales for community $i$, period $t$

$$
\begin{aligned}
& \Delta \mathrm{L}_{\mathrm{it}}=\mathrm{L}_{\mathrm{it}}-\mathrm{L}_{\mathrm{it}-1} \\
& \Delta \mathrm{S}_{\mathrm{it}}=\mathrm{S}_{\mathrm{it}}-\mathrm{S}_{\mathrm{it}-1}
\end{aligned}
$$

and the $\mathrm{MM}_{\mathrm{i}}, \mathrm{D}_{\mathrm{i}}$, and $\mathrm{CS}_{\mathrm{i}}$ are the community and bank market characteristics defined earlier. The $\epsilon_{i t}$ terms in each equation are the random disturbances satisfying the standard statistical assumptions. ${ }^{7}$

\section{Estimation Results}

Parts A and C of Table 1 present the results of the Granger test for causality when sales and changes in sales are used as an explanatory variable for bank lending activity. The regression results using loans and changes in loans as exogenous variables are provided in parts $B$ and $D$ of the same table. The findings presented in Table 1 provide support for the alternative hypothesis that the volume of loans and changes in loan volume are sensitive to past economic activity. The coefficients on the lagged retail sales variables are positive and the t-statistic values on the coefficients of $\beta(1)$ in regression $A$ and $\beta(2)$ in regression $C$ are significantly different from zero at the five percent level. Moreover, the joint F-statistic on the coefficients of the retail sales variables $(\beta(1)$ and $\beta(2)$ are also significantly different from zero at the five percent level. Thus, Granger's test for causality indicates that economic activity "leads" or contains information exploitable in forecasting community bank loans. That is, the significant F's on the coefficients of the retail sales variables indicate that the predictions of loans based on past values of loans and sales are significantly better than loan predictions conditional on just past values of loans.

In the two equations where retail sales and 
Table 1

Tests for Causality Between Loans and Retail Sales

$$
Y_{i}(t)=\sum_{m=1}^{2} \alpha(m) Y_{i}(t-m)+\sum_{n=1}^{2} \beta(n) X_{i}(t-n)+\sigma_{1} M M_{i}+\sigma_{2} D_{i}+\sigma_{3} C_{i}+\sigma_{4} t+\sigma_{0}
$$

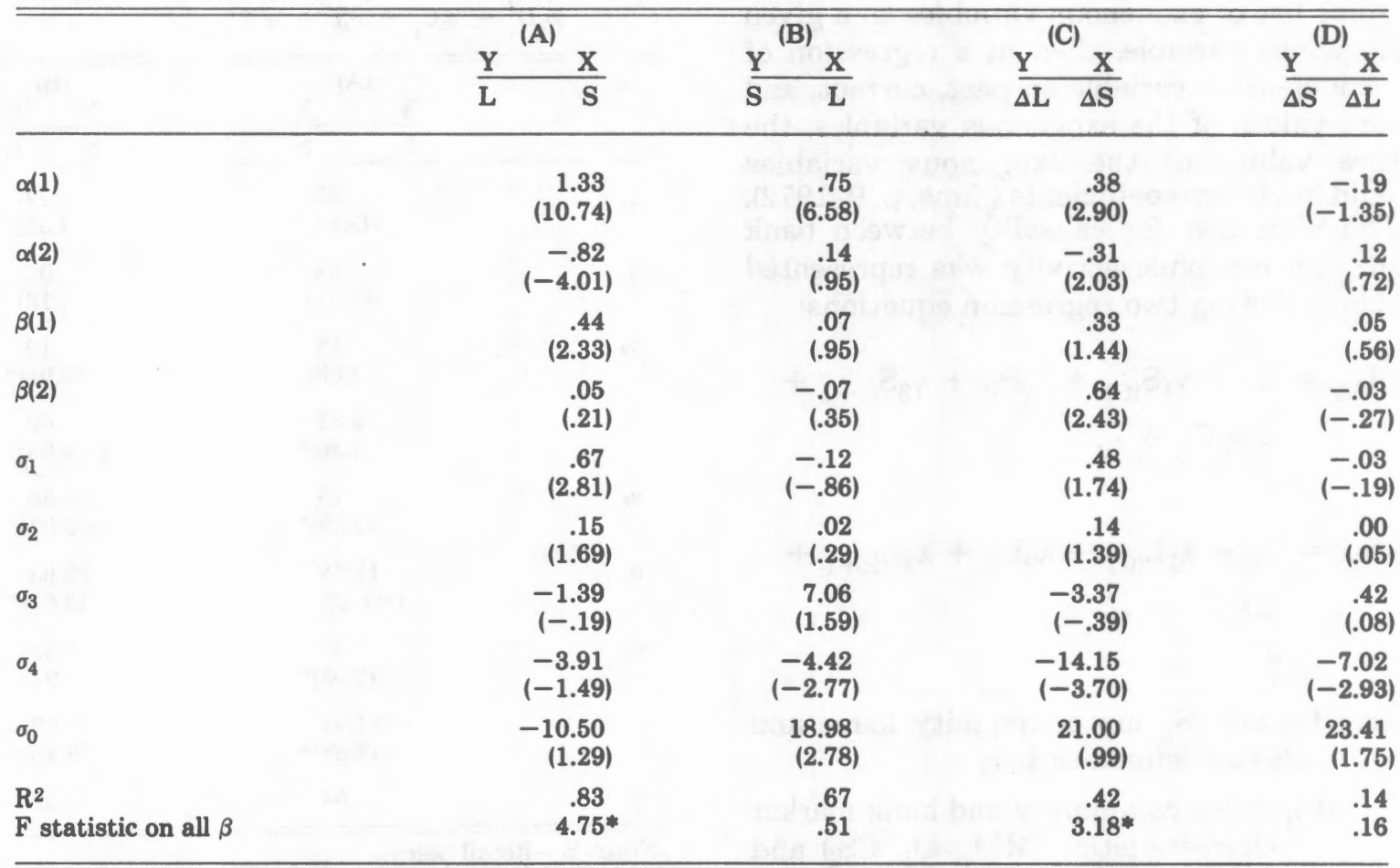

\footnotetext{
Note: S-Retail Sales

L-Loans

t -statistics for coefficients appear in parenthesis below relevant coefficients

* - significant at 5 percent level $\left(F_{2,97}\right)$
}

changes in retail sales are regressed on loans and changes in loans, the coefficients on the lagged loan variables are never jointly significantly different from zero at the five percent level. Moreover, the coefficients on the loan variables are always quite small relative to the values obtained when retail sales are the explanatory variable for loans. Thus, the hypothesis that lagged loans are not informative about or useful in predicting local economic activity cannot be rejected.

Community and bank market characteristics significant at the five percent significance level include percent of community employment in mining and manufacturing (MM), distance to nearest city of equal or larger size (D), and existence of alternative credit sources (CS). Unexpectedly, mining and manufacturing employment was positively related to total loans. This positive correlation probably results from the large volume of consumer loans in Arizona's mining communities, thus obscuring the negative effect of external credit access on local loan activity. Distance from other communities which offer similar or higher-ordered goods and services was the proxy for intercommunity competition for and leakages of loans and retail sales. While loan volume was higher in geographically isolated communities, no relationship was discerned between retail sales and distance. The existence of alternative credit sources exhibited no influence on loan volume but a positive relationship to growth in community sales. This positive relationship may reflect the prospensity of saving and loans and credit unions to establish offices in the more rapidly growing rural communities. Finally, the negative coefficient on the trend variable is the consequence of the cyclinal downturn in loans and sales during 1979 and $1980 .^{\circ}$

An alternative statistical test of causality, developed by Sims (1972), was applied to provide additional evidence for the economic 
activity-bank lending relationship. The basic premise of the Sims test is that the past can "cause" the future but the future cannot "cause" the past. More specifically, if causality runs one way from current and past values of some list of exogenous variables to a given endogenous variable, then in a regression of the endogenous variable on past, current, and future values of the exogenous variables, the future values of the exogenous variables should have zero coefficients (Sims, p. 9, 1972).

The Sims test for causality between bank loans and economic activity was represented by the following two regression equations:

$$
\begin{aligned}
\mathrm{L}_{\mathrm{it}}= & \gamma_{\mathrm{o}}+\gamma_{1} \mathrm{~S}_{\mathrm{it}-1}+\gamma_{2} \mathrm{~S}_{\mathrm{it}}+\gamma_{3} \mathrm{~S}_{\mathrm{it}+1}+ \\
& \underset{\mathrm{j}}{\Sigma} \gamma_{\mathrm{ij}} \mathrm{C}_{\mathrm{ij}}+\epsilon_{\mathrm{it}}
\end{aligned}
$$

(6) $\mathrm{S}_{\mathrm{it}}=\lambda_{\mathrm{o}}+\lambda_{1} \mathrm{~L}_{\mathrm{it}-1}+\lambda_{2} \mathrm{~L}_{\mathrm{it}}+\lambda_{3} \mathrm{~L}_{\mathrm{it}+1}+$

$$
{ }_{\mathrm{j}}^{\Sigma} \lambda_{\mathrm{ij}} \mathrm{C}_{\mathrm{ij}}+\epsilon_{\mathrm{it}}
$$

where: $\mathrm{L}_{\mathrm{it}}$ and $\mathrm{S}_{\mathrm{it}}$ are community loans and sales as defined earlier,

$\mathrm{C}_{\mathrm{ij}}=$ the community and bank market characteristics $\left(\mathrm{MM}_{\mathrm{i}}, \mathrm{D}_{\mathrm{i}}, \mathrm{CS}_{\mathrm{i}}\right)$ and the trend variable $(t)$.

If sales "cause" loans but the causality is not reversed, the coefficients on the lagged sales variable in equation $5\left(\gamma_{1}\right)$ and the future loan variable in equation $6\left(\lambda_{3}\right)$ will be significantly different from zero. Alternatively, if loans lead sales, $\gamma_{3}$ and $\lambda_{1}$ will be significantly different from zero. Finally, if bidirectional causality or feedback occur, the coefficients of the past and future exogenous variables in both equations 5 and 6 will be significantly different from zero. ${ }^{\circ}$

The results of the Sims test for the direction of causality are provided in Table 2. In the equation where $L_{i t}$ is the dependent variable, the coefficient of past retail sales is positive and significantly different from zero at the five percent level while the coefficient on future sales is insignificant. Moreover, when sales are the dependent variable, only the coefficient on future loans is significantly different from zero. These combinations indicate a unidirectional causality running from sales to loans. Thus the Sims test provides additional support for the hypothesis that economic activity leads bank lending.

Table 2

\begin{tabular}{|c|c|c|}
\hline \multirow[t]{3}{*}{1} & (A) & (B) \\
\hline & $\underline{\mathbf{Y}} \mathbf{X}$ & $\mathbf{Y} \quad \mathbf{X}$ \\
\hline & $\mathbf{L}$ & L \\
\hline$\gamma_{1}$ & $\begin{array}{c}.95 \\
(3.14)^{*}\end{array}$ & $\begin{array}{c}.77 \\
(.55)\end{array}$ \\
\hline$\gamma_{2}$ & $\begin{array}{c}.42 \\
(1.41)\end{array}$ & $\begin{array}{l}.02 \\
(.16)\end{array}$ \\
\hline$\gamma_{8}$ & $\begin{array}{l}.18 \\
(.83)\end{array}$ & $\begin{array}{c}.19 \\
(3.08)^{*}\end{array}$ \\
\hline$\sigma_{1}$ & $\begin{array}{c}1.31 \\
(4.56)^{*}\end{array}$ & $\begin{array}{c}-.69 \\
(-4.95)^{*}\end{array}$ \\
\hline$\sigma_{2}$ & $\frac{.25}{(2.29)^{*}}$ & $\begin{array}{c}-.06 \\
(-1.07)\end{array}$ \\
\hline$\sigma_{8}$ & $\begin{array}{l}-11.52 \\
(-1.17)\end{array}$ & $\begin{array}{l}15.93 \\
(3.63) *\end{array}$ \\
\hline$\sigma_{4}$ & $\begin{array}{l}7.18 \\
(2.05)^{*}\end{array}$ & $\begin{array}{c}1.52 \\
(.94)\end{array}$ \\
\hline$\sigma_{0}$ & $\begin{array}{c}-101.94 \\
(3.68)^{*}\end{array}$ & $\begin{array}{l}77.66 \\
(6.49)^{*}\end{array}$ \\
\hline $\mathbf{R}^{2}$ & .54 & .52 \\
\hline
\end{tabular}

Sim's Test for Causality Between Loans and Retail Sales $\begin{aligned} & Y_{i}(t)= \gamma_{1} X_{i}(t-1)+\gamma_{2} X_{i}(t)+\gamma_{2} X_{i}(t+1)+\sigma_{1} M M_{i}+ \\ & \sigma_{2} D_{i}+\sigma_{2} C_{i}+\sigma_{4} t+\sigma_{0}\end{aligned}$

Note: $\mathrm{S}$ - Retail Sales
$\mathrm{L}$-Loans
$\mathrm{t}$ - statistics for coefficients appear in
$\quad$ parenthesis below relevant coefficients
*-significant at 5 percent level

\section{Conclusion}

The findings of our statistical analysis in. dicate that community economic activity and bank lending are related. This is consistent with the results of earlier studies. However, the results of the Granger and Sims tests for causality suggest that the principal direction of "causality" is from economic activity to loans and not the reverse. That is, while Arizona's banks obviously facilitated the growth process in non-metropolitan communities, there exists no evidence to support the hypothesis that the branch banks initiated the growth process.

The lack of any statistical support for the hypothesis that loans lead economic activity may have resulted from the use of retail sales as our proxy for economic activity. That is, it might be argued that bank loans did "cause" or "lead" changes in community employment or income levels, yet these changes were simply not reflected in retail sales. For example, if 


\section{Commercial Bank Loans and Non-Metropolitan Economic Activity: A Question of Causality 31}

bank loans did lead employment and consumer spending, yet most of the increase in consumer spending "leaked-out" to other communities, no statistically significant relationship between local loans and local retail sales would be evident. However, the non-metropolitan Arizona communities in our sample are relatively geographically isolated and the local multipliers of these communities averaged about 1.5 (Gibson and Worden). Therefore, while employment, income and retail sales may not be perfectly correlated, it is not unreasonable to anticipate some changes in community retail sales if employment and income were influenced by loans. Yet, no impact was statistically discernible.

A more realistic explanation of the passive behavior of banks is that banks have relatively short-term liabilities, and as a result, they favor short- and intermediate-term lending activities or investments in liquid assets. Therefore, it may be unrealistic to expect banks to provide the long-term credit necessary for the expansion or development of export sectors.

In summary, our findings concur with those of Dreese (1974) and suggest that commercial banks did not play a very significant role in the growth of non-metropolitan Arizona. However, the Arizona banking system is dominated by three large branch banks and our results may not be representative of bank behavior elsewhere. The use of causality tests on bank lending and economic activity in other states should be undertaken to determine the applicability of our findings to other regions and banking systems.

\section{FOOTNOTES}

'Commercial banks are the focus of this study because of their great importance in the financial market. For example, commercial banks hold more than forty percent of the total assets of financial intermediaries. This represents almost three times the amount of assets held by their closest rivals, savings and loan associations.

'Some of these earlier studies used lagged variables in their analysis of the bank loans-community development relationship, however, their model specifications did not permit tests of the direction of causality between loans and economic activity.

'The test statistic of the null hypothesis that a set of regression coefficients is zero is

$$
\frac{\text { RESS-UESS }}{\text { UESS }} \times\left(\frac{N-K}{r}\right)
$$

where RESS = error sum of squares in the restricted model

UESS = error sum of squares in the unrestricted model

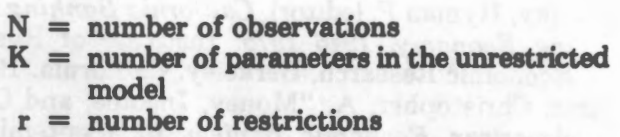

The test statistic will have an $\mathbf{F}$ distribution with $\mathbf{r}$ degrees of freedom in the numerator and $N-K$ in the denominator.

Outstanding loans are sometimes considered a less than accurate representation of local lending activity by the community's banks because of cross-bank loan participation. The nature of our data from individual branch offices in Arizona should greatly overcome this shortcoming because branch banks reported loans for the specific community involved and cross-office loan participation was represented.

For example, the 1976 indices of deflated retail sales $\left(S_{i, 76}\right)$ and loans $\left(L_{i, 76}\right)$ for community $i$ are:

$$
\begin{aligned}
& S_{i, 76}=\frac{1976 \text { real retail sales community } i}{1975 \text { real retail sales community } i} \times 100 \\
& L_{i, 76}=\frac{1976 \text { real loans community } i}{1975 \text { real loans community } i} \times 100
\end{aligned}
$$

'The Granger technique is usually applied to strictly time series data. However, Steinnes $(1977,1978)$ has demonstrated that the technique may also be applied to pooled time series cross-sectional data bases, provided care has been taken to insure that autocorrelation and heteroscedasticity are not a problem.

'Autoregressive processes involving three and four lags of the dependent variable were also tried, however, the third and fourth lags were not significant and did not improve the predictive power of the models.

An examination of the residuals (both cross sectional and time series) provided no indication that either heteroscedasticity or serial correlation was a problem. This was anticipated since the loan and sales data were expressed as indices.

In the case where only one past and one future parameter is specified, the $t$ test may be substituted for the joint F test.

\section{REFERENCES}

Dreese, G. Richard. "Banks and Regional Economic Development." Southern Economic Joumal. 40 (April, 1974): 647-656.

Gibson, Lay James and Marshall Worden, "Estimating the Economic Base Multiplier: A Test of Alternative Procedures." Economic Geography (Spring 1980): 146-159.

Granger, C. W. J. "Investigating Causal Relationships by Econometric Models and Cross-Spectral Methods." Econometrica. 37 (July, 1969): 424-438.

Griggs, Jack and William Petty. Loan Practices of Commercial Banks and Economic Agglomenation. University of Texas-Austin, Program on the Role of Growth Centers in Regional Economic Development, Center for Economic Development, 1970.

Ho, Yan Ki and Ron E. Shaffer. "Commercial Banking Performance and Local Economic Activities." Paper presented at Mid-Continent Section Meetings of Rogional Science Association. Department of Agricultural Economics, University of Wisconsin-Madison, 1979.

Macesich, George. Commercial Banking and Regional Development in the U.S., 1950-1960. Tallahassee, Florida: Florida State University, 1965.

McGee, L. R. "Commercial Banking in Growth Regionals." Discussion Paper Number 34, Lexington, Kentucky: University of Kentucky, 1970. 
Minsky, Hyman P. (editor). California Banking in a Growing Economy, 1946-1975. Institute of Business and Economic Research, Berkeley, California. 1965.

Sims, Christopher, A. "Money, Income, and Causality." American Economic Review. 62 (September, 1972): 540-552.

Steinnes, Donald N. "Causality and Intraurban Location." Journal of Urban Economics 4 (January, 1977): 69-79. Steinnes, Donald N. "Causality and Migration: A Statistical Resolution of the 'Chicken or Egg Fowl-up."' Southern Economic Journal. 45 (July, 1978): 218-226. 